\title{
Crohn's disease presenting as a colonic free perforation: A rare case report
}

\author{
Ankush Sarwal ${ }^{1, *}$, Neetika Sarwal ${ }^{2}$ \\ ${ }^{\mathbf{1}} \mathrm{HOD}$, Institute of Minimal Access and Gi Surgery, Sarwal Hospital, Ambala, Haryana, ${ }^{2}$ Junior Resident, Dept. of Anaethesia, \\ Maharishi Markandeshwar Institute of Medical Sciences and Research, Ambala, Haryana, India
}

*Corresponding Author:

Email: drankushsarwal@yahoo.in

\begin{abstract}
"Crohn's disease (CD) is a chronic and relapsing inflammatory bowel disease (IBD) that can affect the entire gastrointestinal tract. Free bowel perforation in CD is a relatively rare complication. In this report, we present a case of free colonic perforation in a patient whose final biopsy came out to be Crohn's disease, which is a rare presentation in a patient with Crohn`s disease and we discuss this rare complication."
\end{abstract}

Keyword: Crohn's disease, Colonic perforation.

\section{Introduction}

Crohn's disease $(\mathrm{CD})$ is a chronic, transmural inflammatory disease of the gastrointestinal tract that can affect any part of the gastrointestinal tract from the lips to the anal margin. The definitive cause of Crohn's disease is unknown although a combination of genetic and environmental factors has been implicated. ${ }^{1}$ Free bowel perforation is relatively rare among the major complications of $\mathrm{CD}$ that include stenosis and fistulae. Free perforation is the most severe and debilitating complication, and requires emergency surgery. While the incidence of $\mathrm{CD}$ remains lower than that in western countries, but the recent increases in its incidence in Asian countries are remarkable. India being a developing country patient is not generally diagnosed until the present to emergency department with complications. $^{2}$ We report a case of free colonic perforation in a patient whose final biopsy came out to be Crohn's disease.

\section{Case Report}

The patient was a 54-year-old male chronic smoker, who was having pain abdomen, abdominal distension and fever for last 10 days for which he was taking pain killers on his own. Previously he had episodes of diarrhoea, for 3 months which he used to take antibiotics on his own and never had an evaluation for the same. On examination he was ill and septic, the abdomen was distended, rigid, and muscular resistance could be felt. X-Ray abdomen in sitting position was done which showed free air under diaphragm. (Fig. 1)

On basis of basis of clinical presentation and $\mathrm{x}$-ray findings, making a provisional diagnosis of perforation peritonitis, the patient was adequately resuscitated and shifted to operating room. Emergent laparotomy was performed in which purulent ascites was found. Stomach, duodenum and rest of small intestine had pus flakes but no peroration was seen .On inspecting colon perforations were found on mesenteric side of ascending colon and transverse colon. Sub-total colectomy was done and the left sigmoid and rectum was taken out as end colostomy as mucous fistula to avoid blind loop (Fig. 2) Post operatively patient was shifted to surgical ICU for 2 days, given iv fluids and parentral nutrition. Patient was then shifted to general ward and started on oral liquid diet on 5th day. The patient recovered gradually and was discharged on 10th post-operative day.

The specimen (Fig. 3) was sent for histopathological examination and the final histopathological examination showed mucosal and submucosal edema microscopically with chronic inflammatory infiltrate extending transmurally and the presence of epitheloid granulomas and hyperplasia of the submucosal nerves which were all diagnostic of Crohn`s disease.

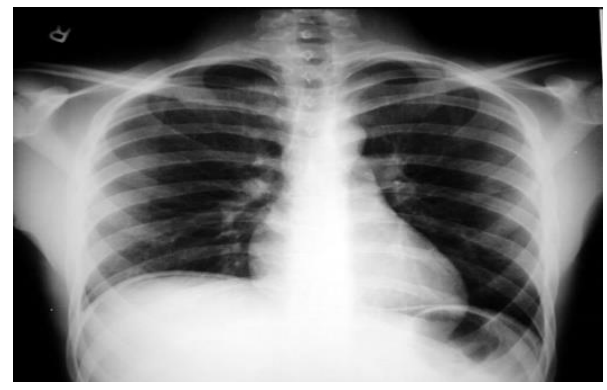

Fig.1: showing free air under diaphram

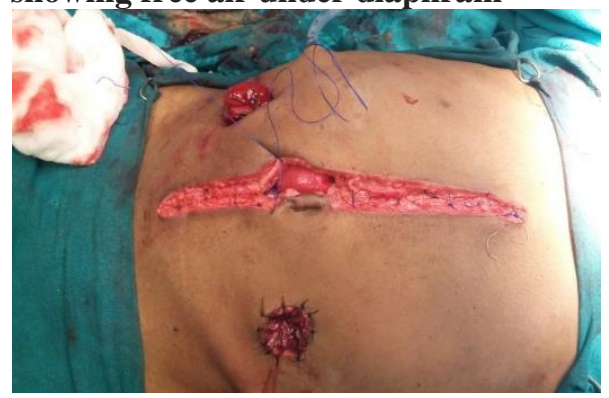

Fig. 2: Final external apperance of opertaive site 


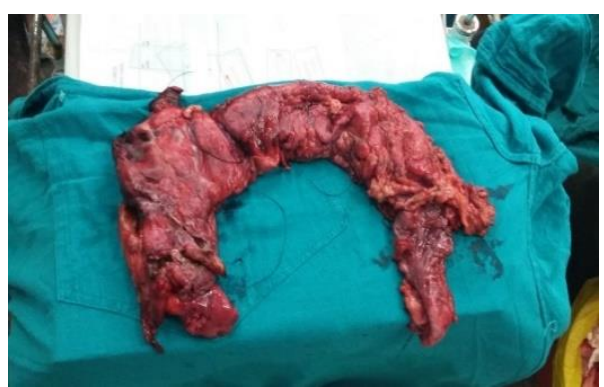

Fig. 3: Resected subcolectomy specimen

\section{Discussion}

Our report discusses a case of undiagnosed Crohn's disease which presented as peritonitis because of a free perforation of the ascending and transverse colon. It is most common in North America and Northern Europe with an incidence of 5 per 10000 . Over the last four decades, there seems to have been a rise in the incidence, which cannot be accounted for by increased diagnosis ${ }^{1}$. It is slightly more common in women than in men, and is most commonly diagnosed in young patients between the ages of 25 and 40 years. There does, however, seem to be a second peak of incidence around the age of 70 years. Although Crohn's disease is thought to be rare and intestinal tuberculosis common in India, Crohn's disease is being reported more often. ${ }^{3}$ The most common clinical manifestations of a patient having Crohn's disease are abdominal pain, diarrhea, and weight loss. Crohn's disease can be complicated by intestinal obstruction or localized perforation with fistula formation. Free bowel perforation in Crohn's disease patients is a relatively rare complication and it is an indication of emergent operation. ${ }^{4,5}$ Its rate of occurrence is reported to be $0.1 \%$ to $0.5 \%$ among surgically treated perorated cases. Williamson et al reported 2 cases of Crohn's disease, in which inflammation was considered to deteriorate to cause perforation. ${ }^{6}$ The largest series report on patients for free perforation in Crohn's disease is by Greenstien et al in which he had published a series of 99 patients. ${ }^{7}$ With regard to the location of free perforation, Greenstein et al. reported that $50.0 \%$ of perforations occur in the ileum and $50.0 \%$ of perforations occur in the colon. Doh et al in their study had dramatically higher incidence of ileal perforations $(86.2 \%)$ as compared to colonic perforations. The Japanese study also reported that $80.0 \%$ of perforations occurrence in the ileum. Thus colonic perforations are even rarer to occur in $\mathrm{CD} .{ }^{8}$

In our case, the patient was an illiterate labourer who had never taken any medical advice for his symptoms and used to take palliative medicines on his own. Initially before operating the patient the provisional pre-operative differential diagnosis was taken as either duodenal ulcer perforation or typhoid intestinal perforation because of the incidence, symptoms, smoking habits and economic status of the patient. ${ }^{9}$ The intra-operative findings were a little out of the box and thus final histopathological biopsy was keenly awaited. When the final histopathological biopsy showed Crohn's disease, it was less expected. Based on the above data patient was started on salicylate therapy and kept on 3 monthly follow up. The patient has been asymptomatic for 1 year and engaged in his routine activities.

\section{Conclusion}

Incidence of $\mathrm{CD}$ in Indian population is lower as compared to western population. But, recent increase in its incidence in Indian population is remarkable. Thus more patients are expected to report to emergency department with complications of $\mathrm{CD}$. Colonic perforation can be a presenting complication of a $\mathrm{CD}$ patient and less literature is there for the same.

\section{References}

1. Logan R.F .Inflammatory bowel disease incidence: up, down or unchanged? Gut 1998;42:309-11.

2. Ng SC, Tang W, Ching JY, Wong M, Chow CM, Hui AJ, et al. Incidence and phenotype of inflammatory bowel disease based on results from the Asia-pacific Crohn's and colitis epidemiology study. Gastroenterol 2013;145:158-65

3. Sood A, Midha V, Sood N, Bhatia AS, Avasthi G. Incidence and prevalence of ulcerative colitis in Punjab, North India. Gut 2003;52:1587-90.

4. Ikeuchi H, Yamamura T. Free perforation in Crohn's disease: review of the Japanese literature. J Gastroenterol 2002;37(2):1020-27.

5. Berg DF, Bahadursingh AM, Kaminski DL, Longo WE. Acute surgical emergencies in inflammatory bowel disease. Am J Surg 2002;184(1):45-51.

6. Williamson ME, Hughes LE. Bowel diversion should be used with caution in stenosing anal Crohn's disease. Gut 1994;35(8):1139-40.

7. Greenstein AJ, Lachman P, Sachar DB, Springhom J, Heimann T, Janowitz HD. Perforating and nonperforating indications for repeated operations in Crohn's disease: evidence for two clinical forms. Gut 1988;29(5):588-92.

8. Doh YS, Kim YS, Bae SI, Im JP, Cheon JH, Ye BD, Kim JW, Park YS, Lee JH, Kim YH, Kim JS, Han DS, Kim WH. The clinical characteristics of patients with free perforation in Korean Crohn's disease: results from the CONNECT study. BMC Gastroenterol 2015 Mar $18 ; 15: 31$.

9. Dorairajan LN, Gupta S, Deo SVS, Chumber S, Sharma L: Peritonitis in India-A decades experience. Tropical Gastroenterol 1995;16(1):33-8. 